\title{
BMJ open Equal cancer treatment regardless of education level and family support? A qualitative study of oncologists' decision-making
}

To cite: Cavalli-Björkman N, Glimelius B, Strang P. Equal cancer treatment regardless of education level and family support? A qualitative study of oncologists' decisionmaking. BMJ Open 2012;2: e001248. doi:10.1136/ bmjopen-2012-001248

- Prepublication history and additional material for this paper are available online. To view these files please visit the journal online (http://dx. doi.org/1036/bmjopen-2012001248).

Received 3 April 2012 Accepted 27 July 2012

This final article is available for use under the terms of the Creative Commons Attribution Non-Commercial 2.0 Licence; see http://bmjopen.bmj.com

${ }^{1}$ Department of Radiology, Oncology and Radiation Science, Uppsala University, Uppsala, Sweden

${ }^{2}$ Department of Oncology and Pathology, Karolinska Institute, Stockholm, Sweden

Correspondence to Dr Nina Cavalli-Björkman; nina.cavalli-bjorkman@ onkologi.uu.se

\section{ABSTRACT}

Objective: Treatment gradients by socioeconomic status have been observed within cancer care in several countries. The objective of this study was to explore whether patients' educational level and social network influence oncologists' clinical decision-making.

Design: Semi-structured interviews on factors considered when deciding on treatment for cancer patients. Interviews were transcribed and analysed using inductive qualitative content analysis.

Setting: Oncologists in Swedish university- and nonuniversity hospitals were interviewed in their respective places of work.

Participants: Twenty Swedish clinical oncologists selected through maximum-variation sampling.

Primary and secondary outcome measures:

Elements which influence oncologists' decision-making process were explored with focus on educational level and patients' social support systems.

Results: Oncologists consciously used less combination chemotherapy for patients living alone, fearing treatment toxicity. Highly educated patients were considered as well-read, demanding and sometimes difficult to reason with. Patients with higher education, those very keen to have treatment and persuasive relatives were considered as challenges for the oncologist. Having large groups of relatives in a room made doctors feel outnumbered. A desire to please patients and relatives was posed as the main reason for giving in to patients' demands, even when this resulted in treatment with limited efficacy.

Conclusions: Oncologists tailor treatment for patients living alone to avoid harmful side-effects. Many find patients' demands difficult to handle and this may result in strong socioeconomic groups being overtreated.

\section{INTRODUCTION}

Over the last few decades, treatment advances in the field of colorectal cancer have resulted in longer survival, irrespective of stage of the disease. With optimal surgical and oncological treatment, 5-year survival, all

\section{ARTICLE SUMMARY}

Article focus

- Do clinical oncologists take patients' family structure and/or social network into consideration when deciding on oncological treatment?

- Are clinical oncologists aware of patients' educational level and, if so, does it affect their clinical behaviour and treatment strategies?

- How do clinical oncologists handle patients' and relatives' demands with regard to information and treatment?

\section{Key messages}

- Clinical oncologists are cautious when treating patients who live alone as they fear that those patients will have difficulty managing treatment toxicity.

- According to oncologists, patients' educational level influences the consultation length, the exchange of information and in some instances, the type of oncological treatment given.

- Swedish oncologists are finding patient demands increasingly difficult to handle and some say it is easier to let patients have the treatment they ask for than argue with patients or relatives.

Strengths and limitations of this study

- This is a qualitative study set in Sweden, where maximum-variation sampling with regard to gender, place of work and age has been used to gain a rich interview material. It is unlikely that a quantitative study had been able to identify the themes which have emerged through interviews between colleagues. As in all qualitative studies, the results are representative of the individuals who have volunteered information in the study and caution should be used before generalising. The strength of the study lies in the findings. Recent data have indicated poorer survival and less intensive oncological treatment for patients who live alone. Although the gradients are large and lonely patients at a significant disadvantage, the reasons for these findings are not known. This study adds new information to the role of social support and socioeconomic status in cancer care. 
stages combined, now lies around $60 \%$ for both colon and rectal cancer. ${ }^{1}$ Concurrently, a large number of studies have shown that patients of low socioeconomic status (SES) have poorer cancer survival than those of higher SES. While cancer treatment continues to evolve, concerns are raised that improvements mainly seem to benefit patients of higher SES and with strong social networks. Patients with high educational level and/or solid social support have a more favourable outcome than patients of low educational level and those who live alone. ${ }^{2-5}$ While comorbidity and lifestyle may account for some of the difference, contributing factors may be inequality in diagnostic activity and treatment between patients of low and high SES. ${ }^{6-8}$

In Sweden, the healthcare system is tax-financed and available to all citizens at nominal cost, regardless of the patient's background or social standing. In addition, national and regional guidelines are regularly issued in order to ensure that patient treatment is fair and equal between different geographical regions. Recent publications indicating unequal treatment due to SES have therefore received much media attention and have created public debate. ${ }^{679}$ If there is a possibility that patients' educational level and/or social support influences cancer treatment decisions, the reasons for this must be explored. To our knowledge, it has not been previously studied whether indicators of SES and social support affect clinical decision-making, and, if so, why.

The aim was to explore the influence of patients' educational level and social network on clinical decisionmaking through interviewing clinical oncologists.

\section{METHODS}

Swedish oncologists working with gastrointestinal cancer were identified in the register of the national society for gastro-intestinal oncology. In total, 20 informants were selected through maximum-variation sampling ${ }^{10}$ with regard to sex, place of work (university or rural hospital) and years of experience as specialists of oncology (table 1). All study participants were contacted by e-mail before they agreed to be interviewed. Approximately half of the participants were completely unknown to the researcher while the other half had met her previously on one or more occasions. No-one refused participation.
One answered too late to be considered for the study but had wanted to be interviewed and one did not reply.

The interviews were conducted by the first author in the informants' places of work, taped and later transcribed in verbatim mode. The first author is an oncologist and as some topics were sensitive it was deemed best that the informants were interviewed by a colleague in the same field. Interviews took between 25 and 45 mins and transcribed ranged from 1858 to 4739 words. Questions were open ended and the interviewer did not follow a fixed list of questions, but aimed to let the informants talk freely on given topics. The main subjects were factors/motives that may influence clinical decision-making other than pure disease-related parameters, such as the role of relatives, the patients' social network and educational level.

The interviews were analysed using inductive qualitative content analysis. ${ }^{11-13}$ The analyses were done by the first and last authors using the following steps: (A) The transcribed interviews were read through to obtain an overall impression (naive reading). (B) The material was re-read carefully to identify significant text segments (meaning units). (C) The meaning units were condensed and abstracted to codes. (D) The codes were then compared and sorted into categories and themes. (E) The categories and themes were compared to the entire interview, to make sure that the interpretation was consistent and coherent with the text as a whole, and that the meaning had not been transformed in the process of the analysis. (F) The categories and themes were compared to avoid overlapping, and content descriptions were developed. (G) Quotations were used to exemplify findings. Main and subcategories are shown in table 2.

The regional ethical committee was consulted and ethical approval for this type of study was not deemed necessary.

\section{RESULTS}

Patients who live alone or who have little social support Almost all oncologists thought that lack of a partner or family was a factor to be taken into consideration when deciding on cancer treatment. Coming unaccompanied to doctors' consultations resulted in a sense of insecurity for the oncologist, who was not sure as to whether the

Table 1 Demographics of informants

\begin{tabular}{|c|c|c|c|c|}
\hline & $\mathbf{n}=$ & $\begin{array}{l}\text { Age in years mean } \\
\text { (range) }\end{array}$ & $\begin{array}{l}\text { Years as specialist of oncology mean } \\
\text { (range) }\end{array}$ & Place of work, $\mathbf{n}=$ \\
\hline Male oncologists & $7(35 \%)$ & $51(39-63)$ & $14(1-26)$ & $\begin{array}{l}\text { University hospital, } 5 \\
\text { Non-university } \\
\text { hospital, } 2\end{array}$ \\
\hline $\begin{array}{l}\text { Female } \\
\text { oncologists }\end{array}$ & $13(65 \%)$ & $49(38-68)$ & $9(1-23)$ & $\begin{array}{l}\text { University hospital, } 8 \\
\text { Non-university } \\
\text { hospital, } 5\end{array}$ \\
\hline
\end{tabular}


patient communicated all the necessary information or whether important instructions concerning cancer treatment were understood by the patient.

\section{Oncologists' perceptions of the patient living alone}

Single patients were seen as less communicative, less keen to have cancer treatment and also at higher risk of substance abuse. When asked about patients who live alone, there were concerns that they could be judged as having poorer performance status (PS) simply due to the lack of a partner. Patients living alone were also considered by some as having lower quality of life (QoL) and less to live for than patients with a partner, and were thus expected to demand less potent cancer treatment.

And there is probably a tendency to believe that the person lying there alone has lower quality of life and less to live for. It's not necessarily so but I think that even if it's hard to admit to yourself it could be that way [the doctor thinks]. (Female oncologist in university hospital (no. 13))

\section{Oncologists' fear of complications}

Patients lacking a partner and/or a social network made oncologists worry about treatment safety. They consciously chose less toxic treatments for patients without family support. In addition, some oncologists opted for intravenous 5-fluorouracil instead of oral capecitabine for patients with a weak social network.

Yes, I think it makes you more cautious with regards to side-effects and how they are handled. You're afraid that the patient will be so sick and weak that they can't care for themselves and then you choose something that you know is not so tough (Female oncologist in rural hospital (no. 8))

The presence of relatives made oncologists feel secure and able to prescribe treatment where severe toxicity was a possibility. Referring patients living alone to a palliative outpatient unit or to a district nurse was

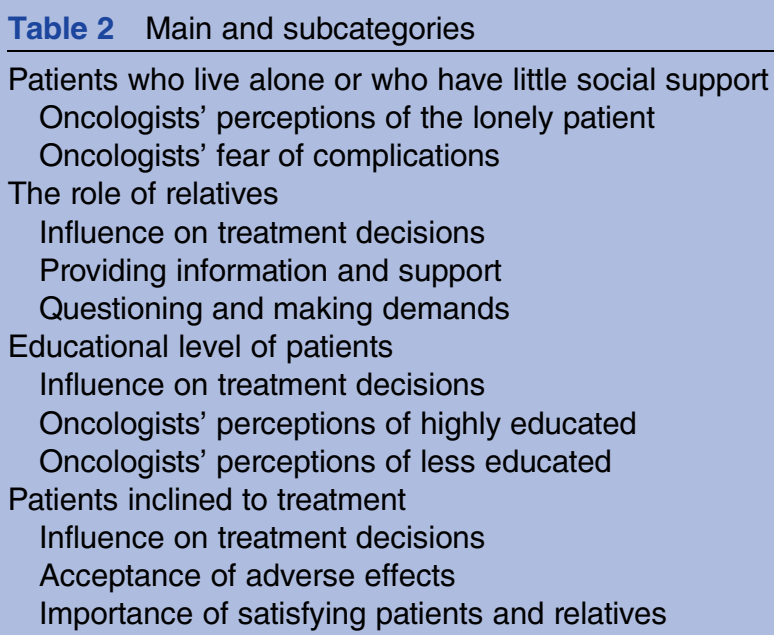

mentioned as a way of compensating for the missing network. It was also suggested that extra time should be dedicated to explaining cancer treatment to patients who live alone, as a means of compensating for their perceived communication difficulties.

\section{The role of relatives}

\section{Influence on treatment decisions}

When asked about the possible influence of accompanying relatives on treatment decisions, there was an agreement that such influence exists. The oncologists were divided on the degree of influence, some saying that it is small and others saying that pressure from relatives is increasing and is sometimes impossible to withstand. Relatives were seen as able to exert influence in two directions: on the patient and on the physician. Patients could be either persuaded by their families to pursue treatment or to discontinue it, and doctors said that at times this pressure on patients was quite strong. An explanation posed was families' anxiety in connection with the cancer diagnosis and their hope that cancer treatment would prolong the life of a loved one. Still, oncologists said they sometimes felt the need to defend their patients when relatives demanded chemotherapy which patients did not feel they could endure.

\section{Providing information and support}

Relatives were seen as an important source of information and oncologists encouraged patients to bring their families for doctor's visits. Doctors strived for good relationships with relatives and said that satisfied patients and relatives were very important to them. They expressed gratitude for the support offered by family members during all phases of cancer treatment and recognised that some treatment was only possible with the support of a spouse.

\section{Questioning and making demands}

In recent years, oncologists felt that there has been a shift in power, and family members are now much more active during cancer treatment. They were described as up-to-date, having scanned the internet and medical literature and often posing specific requests with regard to treatments. While some doctors felt that this was stimulating and led to good discussions during consultations, others said that they felt their professional knowledge was being questioned.

Dr: “...well there are some relatives who are pushy and well-read and maybe have a lot from the internet, that make you feel a little uncomfortable. That they're almost threatening, not threatening but...

Interviewer: ...pressuring...?

Dr: Pressuring! (Female oncologist in rural hospital (no. 12)) 
Having a large number of relatives in the room lent an air of imbalance and doctors admitted feelings of inadequacy and of being outnumbered.

So it's a difficult situation when there are many sitting there. It's easier when there is only one couple (Female oncologist in university hospital (no. 2))

Especially demanding situations were when relatives were highly educated, but not in the medical field, as searching for data can increase anxiety when one cannot fully interpret the information. Another group with emotionally strong influence were parents of young patients, who were described as fighting for their (adult) children's lives, and doing everything in their power to shorten waiting times and hasten cancer treatment.

\section{Educational level of the patients}

Influence on treatment decisions

Evidence of differences in treatment by educational level was uncomfortable and oncologists expressed distress over this injustice. Not all oncologists agreed that they take the patients' educational level into account when deciding on treatment, but most agreed that treatment gradients between patients of low and high educational level do exist. Those who said they were unaffected by the patients' educational level still thought it was possible that other oncologists took it into consideration.

But it's pretty awful to know from these studies that there are differences. I really think so. It doesn't feel good. But I think I too...I think that I too tend to give treatment. To that group of patients. (Female oncologist in a university hospital (no. 14))

\section{Oncologists' perceptions of highly educated}

Patients with higher education were described as wellread, having studied the relevant literature before their first visit. Often these patients came with article reprints, information on clinical trials and had many questionssome of which could be quite difficult to answer. The doctors were divided on whether communication was easier with highly educated patients-some thought it was stimulating to speak to patients 'on the same level' while others thought conversation was more difficult when questions were many and demands were high.

It makes ME feel a little bit safer...a highly educated patient is more often well-read, has been online, is motivated and understands...can ask questions and has less anxiety...I tend to treat patients who are motivated (Male oncologist in university hospital (no. 1))

The theoretical discussions these patients expected were considered as an obstacle to more emotional patient-doctor contact and communication. Oncologists said that highly educated patients often had strong social networks that was an advantage in the treatment setting but which also multiplied the number of people making demands on the doctor. One physician said that highly educated patients expect attention, and more than one described very specific requests posed with regard to therapy. While some doctors refused to give into these demands, others said that there is neither enough time nor energy to argue and it is easier to give the patients what they want.

\section{Oncologists' perceptions of less educated}

Patients of low educational level were described as unobtrusive and compliant, not posing as many questions as patients with higher education.

...patients who basically proclaim that I have this disease and I'll do as the doctor says. And they're satisfied. (Male oncologist in a university hospital (no. 6))

There was a fear that they did not ask enough and that the doctors had not managed to communicate important information about treatment. When asked to speculate on why patients with lower educational level were given less oncological treatment than highly educated, poor compliance, more prevalent substance abuse, communication difficulties, immigrant status and poorer social networks were offered as possible explanations. Interestingly, another suggestion was that doctors are subconsciously prejudiced and believe the above, which make them less inclined to treat patients with lower education level.

\section{Patients who are very eager to receive treatment Influence on treatment decisions}

In Sweden there is a term for patients especially eager to have medical treatment; 'behandlingsbenägen', which roughly translates as 'inclined to treatment'. It is mostly used in cancer settings for patients or relatives who have a very strong wish to extend treatment, even past that which is evidence based. When asked about the influence of such requests on their treatment decisions, oncologists said that it was difficult not to take them into consideration. Patients with this inclination were described as motivated, prepared to accept treatment toxicity and often of higher educational level. Oncologists felt that the phenomenon of patients demanding or strongly arguing for treatment had become more common in later years. Younger, more inexperienced doctors may have a harder time resisting patients' demands than older colleagues, but even very experienced oncologists admitted that this was difficult for them.

Anxiety and fear of progressive disease were considered to be underlying difficulties for these patients, and oncologists admitted that sometimes chemotherapy was used to treat this anxiety, even when the cancer had become resistant to treatment. Some oncologists saw nothing wrong with this practice and defended it by saying that it is wrong to withdraw hope by ending treatment. Reasoning with patients 'inclined to treatment' was difficult and getting 
messages across to individuals who verged on panic was not an easy task. The great majority of doctors said that such patients need much more time than what is available, and communication difficulties often result in dissatisfied patients or relatives.

\section{Acceptance of adverse effects}

One positive aspect of caring for patients 'inclined to treatment' was their willingness to accept the adverse sides of cancer therapy. Oncologists felt safe prescribing treatment as patients were well informed of possible side-effects and ready to tolerate them. There was agreement that these patients are overtreated and that objectively this practice does not prolong survival but rather results in more side-effects and poorer QoL. There was also a concern that patients exposed to repeated treatments do not have sufficient time for psychological adaptation to, and acceptance of, their progressive diseases.

\section{Importance of satisfying patients and relatives}

Patient satisfaction was of the utmost importance to the informants. Oncologists feared that saying no to a treatment the patient or relatives requested would result in an angry patient who rejected the doctor. Many doctors told of such situations, or where the patient had gone for second opinion and been recommended a different line of action than what the interviewed oncologist had proposed. This was described as difficult to handle, leading to feelings of inadequacy and posing a strain on the doctor-patient relationship. Because of this, doctors called for collegiality when offering second opinion and for physicians supporting one another in situations where patients are dissatisfied.

Sometimes you feel, when you have patients who are high consumers of healthcare, you feel that you have failed at being that patient's safety and stability. And instead the substitute for that are a lot of blood tests and $\mathrm{x}$-rays that you order. But-us doctors, we want to comply. We want to see happy patients (Male oncologist in a university hospital (no. 18))

\section{DISCUSSION}

The interviewed gastro-intestinal oncologists were aware of the patients' educational levels and of their family structure, and said that these factors were often included alongside with disease characteristics when deciding on which treatment to recommend their patients. Some argued it was a subconscious observation and that adaptation of treatment was in the patients' best interest. This is consistent with previous findings, showing that patients' SES, life circumstances and social network influence physicians' decisions. ${ }^{14}{ }^{15}$ In an American setting, Bernheim showed that clinical decision-making was influenced by patients' SES but physicians believed this was best for their patients. ${ }^{16}$
Recently, attention has been paid to cancer patients who live alone, who tend to present with more advanced disease. ${ }^{17}{ }^{18}$ Having a partner or having solid social support can reduce cancer mortality by between $12 \%$ and $25 \% .{ }^{19}$ The exact mechanism behind the beneficial effect is not known. In a Scandinavian cohort study, data show that patients who live alone receive less combination chemotherapy for metastatic colorectal cancer than those who live with someone. ${ }^{4}$ An American group has reported striking differences in survival for unpartnered men compared to married men with head-neck cancer, who were treated within clinical protocols. ${ }^{2}$ In that study, low income-patients and those who lived alone had significantly poorer survival after correction for PS and tumour characteristics. This would imply that social network is important even when there is no inequality in treatment, possibly mediated through support during cancer therapy.

In studies on social support, marital status, having children and friends along with congregation membership have been used as measures of social support. However, in a previous register study on Scandinavian cancer patients, we found that several patients registered as married did not live with their spouse. ${ }^{4}$ Although having children can indicate strong support for some patients, others do not retain close relations with their adult offspring. The oncologists in this study have thus been allowed to judge patients' social network through their own contact with patients and relatives.

A main finding in this interview study was that doctors were concerned about patients' ability to handle treatment side-effects. Patients who were single or who had poor social networks were consciously given less toxic (and thus less potent) treatment because of fear of potentially harmful or fatal toxicity. This is an attempt by the oncologists to individually tailor cancer treatment to the patients' life circumstances and cannot be considered an expression of discrimination. It is, however, possible that prejudiced views on people who live alone may influence clinical decisions negatively. One oncologist said that patients who do not come to the consultation with a partner automatically seem to have poorer PS. Doctors' perceptions of patients are known to be subconsciously influenced by patients' SES, ${ }^{20}$ and being alone may be perceived as being unable to cope with cancer treatment.

Undoubtedly, relatives play an important role in the care of cancer patients and their presence may even prolong survival. ${ }^{321}$ The interviewed oncologists encouraged patients' relatives to be actively involved but were aware of the changing climate where patients' and families' demands on doctors steadily increase. This lead to conflicting feelings for doctors who felt their authority was challenged, their time insufficient and the information needs of relatives often unmet. A basic driving force which united oncologists was a desire to please patients and relatives. Requests for second opinion indicate that patient satisfaction is increasingly difficult for doctors to 
achieve. This phenomenon has been described in an American context and the implications for oncologists facing these challenges are further explored there. ${ }^{22}$

Doctors are known to adapt their communication styles and clinical behaviour to patients' educational level. ${ }^{23}{ }^{24}$ Siminoff et al. ${ }^{25}$ showed that doctors spend more time on communication with patients of higher education, while Shin et ll $^{26}$ finds in a Korean study that patients with university education are dissatisfied with consultation times, which they feel are too short. A clinical dilemma oncologists face is that most research shows that patients with lower SES need more time and more resources. ${ }^{27} 28$ Patients with lower education and income have been repeatedly shown to need intensified support to understand medical information-indeed the term 'health literacy' has come in use to describe this group. ${ }^{2329}$ The Swedish oncologists say they are instead devoting much of their time to highly educated patients' questions and demands. Succumbing to pressure from patients may be one explanation as to why clinical management differs between patients of low and high SES. There is evidence to support different practices by SES with regard to screening, clinical investigations, treatment and follow-up, ${ }^{6} 3031$ and a possible explanation is simply that doctors try to meet highly educated patients' requests. This could result in overtreatment of the highly educated, while patients with lower education would receive standard or possibly substandard treatment modified from clinical guidelines.

Many of the Swedish oncologists stated they relied on regional or national guidelines and multidisciplinary team (MDT) conferences when designing treatment for patients. However, the ultimate decision on treatment is made after the MDT. In both Europe and the USA, studies have shown that oncologists tend to vary in their adherence to clinical guidelines. ${ }^{32}{ }^{33}$ It is, however, important to recognise that treatment guidelines are blunt and need to be adapted to the individual patient's situation. Sometimes it may not be feasible to administer treatment according to guidelines because of the patient's life circumstances, age or lack of social or financial support. ${ }^{14}$

In conclusion, educational level and family support affect patient-doctor interactions and, in some instances, cancer treatment. It is likely that on a larger scale this contributes to differences in treatment between patients of different educational level and with different social situations. Awareness of special needs of low SES groups alongside with conscious efforts to provide equal treatment regardless of SES and family support seems essential if gradients are to be reduced. Meeting the expectations of highly educated patients is proving to be a challenge for oncologists and is a future area of research and discussion.

Acknowledgements We would like to thank Kajsa Nordholm for excellent secretarial assistance.

Contributors NC-B has been involved in study design, recruitment of informants, conducting all interviews and transcribing half of them. She has also analysed data and written the manuscript. BG has been involved in study design and in revision of the manuscript. PS has contributed to the study design and done all analysis and condensation of data together with NC-B and revision of the manuscript.

Funding Financial support was provided through the regional agreement on medical training and clinical research (ALF) between Uppsala County Council and Uppsala University. The study was also supported by the Swedish Cancer Society, Stockholm County Council.

Competing interests None.

Ethics approval The Uppsala ethics committee was consulted and their opinion was since this study concerns oncologists who have volunteered to participate, and not patients, approval from them was not necessary.

Provenance and peer review Not commissioned; externally peer reviewed.

Data sharing statement All transcribed interviews and records from the analysis process are kept by the authors and will be used for further future study.

\section{REFERENCES}

1. Nedrebo BS, Soreide K, Eriksen MT, et al. Survival effect of implementing national treatment strategies for curatively resected colonic and rectal cancer. Br J Surg 2011;98:716-23. doi: 10.1002/ bjs.7426.

2. Konski AA, Pajak TF, Movsas B, et al. Disadvantage of men living alone participating in Radiation Therapy Oncology Group head and neck trials. J Clin Oncol 2006;24:4177-83. doi: 24/25/4177 (pii) 10.1200/JCO.2006.06.2901.

3. Holt-Lunstad J, Smith TB, Layton JB. Social relationships and mortality risk: a meta-analytic review. PLoS Med 2010;7:e1000316. doi: 10.1371/journal.pmed.1000316.

4. Cavalli-Bjorkman N, Qvortrup C, Sebjornsen S, et al. Lower treatment intensity and poorer survival in metastatic colorectal cancer patients who live alone. Br J Cancer 2012;107:189-94. doi: 10.1038/bjc.2012.186 bjc2012186 (pii).

5. Byers TE, Wolf HJ, Bauer KR, et al. The impact of socioeconomic status on survival after cancer in the United States: findings from the National Program of Cancer Registries Patterns of Care Study. Cancer 2008;113:582-91. doi: 10.1002/ cncr.23567.

6. Cavalli-Bjorkman N, Lambe M, Eaker S, et al. Differences according to educational level in the management and survival of colorectal cancer in Sweden. Eur J Cancer 2011;47:1398-406. doi: S0959-8049(10)01202-5 (pii) 10.1016/j.ejca.2010.12.013.

7. Olsson LI, Granstrom F, Glimelius B. Socioeconomic inequalities in the use of radiotherapy for rectal cancer: a nationwide study. Eur $J$ Cancer 2011;47:347-53. doi: S0959-8049(10)00246-7 (pii) 10.1016/ j.ejca.2010.03.015.

8. Aarts MJ, Lemmens VE, Louwman MW, et al. Socioeconomic status and changing inequalities in colorectal cancer? A review of the associations with risk, treatment and outcome. Eur $J$ Cancer 2010;46:2681-95. doi: S0959-8049(10)00367-9 (pii) 10.1016/j. ejca.2010.04.026.

9. Eaker S, Halmin M, Bellocco R, et al. Social differences in breast cancer survival in relation to patient management within a National Health Care System (Sweden). Int J Cancer 2009;124:180-7. doi: 10.1002/ijc.23875.

10. Elo S, Kyngas $\mathrm{H}$. The qualitative content analysis process. J Adv Nurs 2008;62:107-15. doi: JAN4569 (pii) 10.1111/ j.1365-2648.2007.04569.x.

11. Patton M. Qualitative research \& evaluation methods. Thousand Oaks: Sage Publications, 2002.

12. Weber RP. Basic content analysis. Newbury Park: Sage Publications, 1990.

13. Hsieh HF, Shannon SE. Three approaches to qualitative content analysis. Qual Health Res 2005;15:1277-88. doi: 15/9/1277 (pii) 10.1177/1049732305276687.

14. Schildmann J, Vollmann J. (Treatment decisions in advanced cancer. An empirical-ethical study on physicians' criteria and the process of decision making). Dtsch Med Wochenschr 2010;135:2230-4. doi: 10.1055/s-0030-1267505.

15. Scott $A$, Shiell $A$, King $M$. Is general practitioner decision making associated with patient socio-economic status? Soc Sci Med 1996;42:35-46. doi: 0277953695000631 (pii).

16. Bernheim SM, Ross JS, Krumholz HM, et al. Influence of patients' socioeconomic status on clinical management decisions: a qualitative study. Ann Fam Med 2008;6:53-9. doi: 6/1/53 (pii) 10.1370/afm.749. 
17. Frederiksen BL, Brown Pde N, Dalton SO, et al. Socioeconomic inequalities in prognostic markers of non-Hodgkin lymphoma: analysis of a national clinical database. Eur $\mathrm{J}$ Cancer 2011;47:910-7. doi: S0959-8049(10)01101-9 (pii) 10.1016/j. ejca.2010.11.014

18. Dalton SO, Frederiksen $\mathrm{BL}$, Jacobsen $\mathrm{E}$, et al. Socioeconomic position, stage of lung cancer and time between referral and diagnosis in Denmark, 2001-2008. Br J Cancer 2011;105:1042-8. doi: 10.1038/bjc.2011.342 bjc2011342 (pii).

19. Pinquart M, Duberstein PR. Associations of social networks with cancer mortality: a meta-analysis. Crit Rev Oncol Hematol 2010;75:122-37. doi: S1040-8428(09)00123-1 (pii) 10.1016/j. critrevonc.2009.06.003.

20. van Ryn M, Burke J. The effect of patient race and socio-economic status on physicians' perceptions of patients. Soc Sci Med 2000;50:813-28. doi: S027795369900338X (pii).

21. Bevan JL, Pecchioni LL. Understanding the impact of family caregiver cancer literacy on patient health outcomes. Patient Educ Couns 2008;71:356-64. doi: S0738-3991(08)00130-4 (pii) 10.1016/j. pec.2008.02.022.

22. Stacey CL, Henderson S, MacArthur KR, et al. Demanding patient or demanding encounter?: A case study of a cancer clinic. Soc Sci Med 2009;69:729-37. doi: S0277-9536(09)00402-X (pii) 10.1016/j. socscimed.2009.06.032.

23. Bao Y, Fox SA, Escarce JJ. Socioeconomic and racial/ethnic differences in the discussion of cancer screening: "between-" versus "within-" physician differences. Health Serv Res 2007:42:950-70. doi: HESR638 (pii) 10.1111/ j.1475-6773.2006.00638.x.

24. Willems S, De Maesschalck S, Deveugele M, et al. Socio-economic status of the patient and doctor-patient communication: does it make a difference? Patient Educ Couns 2005;56:139-46. doi: S0738399104000990 (pii) 10.1016/j.pec.2004.02.011.
25. Siminoff LA, Graham GC, Gordon NH. Cancer communication patterns and the influence of patient characteristics: disparities in information-giving and affective behaviors. Patient Educ Couns 2006;62:355-60. doi: S0738-3991(06)00193-5 (pii) 10.1016/j. pec.2006.06.011.

26. Shin DW, Park JH, Shim EJ, et al. Predictors and outcomes of feeling of insufficient consultation time in cancer care in Korea: results of a nationwide multicenter survey. Support Care Cancer 2011;20:1965-73.

27. Hendren S, Chin N, Fisher S, et al. Patients' barriers to receipt of cancer care, and factors associated with needing more assistance from a patient navigator. J Natl Med Assoc 2011;103:701-10.

28. Matsuyama RK, Wilson-Genderson M, Kuhn L, et al. Education level, not health literacy, associated with information needs for patients with cancer. Patient Educ Couns 2011;85:e229-36. doi: S0738-3991(11)00188-1 (pii) 10.1016/j.pec.2011.03.022.

29. Santoso JT, Engle DB, Schaffer L, et al. Cancer diagnosis and treatment: communication accuracy between patients and their physicians. Cancer J 2006;12:73-6.

30. Gorin SS, Ashford AR, Lantigua R, et al. Intraurban influences on physician colorectal cancer screening practices. J Natl Med AssoC 2007;99:1371-80.

31. Kikano GE, Schiaffino MA, Zyzanski SJ. Medical decision making and perceived socioeconomic class. Arch Fam Med 1996;5:267-70.

32. Lemmens VE, van Halteren $\mathrm{AH}$, Janssen-Heijnen $\mathrm{ML}$, et al. Adjuvant treatment for elderly patients with stage III colon cancer in the southern Netherlands is affected by socioeconomic status, gender, and comorbidity. Ann Oncol 2005;16:767-72. doi: mdi159 (pii) 10.1093/annonc/mdi159.

33. Keating NL, Landrum MB, Klabunde CN, et al. Adjuvant chemotherapy for stage III colon cancer: do physicians agree about the importance of patient age and comorbidity? J Clin Oncol 2008;26:2532-7. doi: 26/15/2532 (pii) 10.1200/JCO.2007.15.9434 